\title{
Breast cancer risk perceptions of Turkish women attending primary care: a cross-sectional study
}

\author{
Mehtap Kartal ${ }^{1 *+}$, Nilgun Ozcakar ${ }^{1 \dagger}$, Sehnaz Hatipoglü ${ }^{2 \dagger}$, Makbule Neslisah $\operatorname{Tan}^{3+}$ and Azize Dilek Guldal ${ }^{1 \dagger}$
}

\begin{abstract}
Background: As the risks and benefits of early detection and primary prevention strategies for breast cancer are beginning to be quantified, the risk perception of women has become increasingly important as may affect their screening behaviors. This study evaluated the women's breast cancer risk perception and their accuracy, and determined the factors that can affect their risk perception accuracy.

Methods: Data was collected in a cross-sectional survey design. Questionnaire, including breast cancer risk factors, risk perceptions and screening behaviors, answered by 624 women visiting primary health care center (PHCC). "Perceived risk" investigated with numeric and verbal measures. Accuracy of risk perception was determined by women's Gail 5-year risk scores.

Results: The mean age of the participants was $59.62 \pm 1.97$ years. Of the women $6.7 \%$ had a first-degree relative with breast cancer, $68.9 \%$ performed breast self-examination and $62.3 \%$ had a mammography, and $82.9 \%$ expressed their breast cancer worry as "low". The numeric measure correlated better with worry and Gail scores. Of the women 65.5\% perceived their breast cancer risk accurately. Among the women in "high risk" group 65.7\% underestimated, while in "average risk" group 25.4\% overestimated their risk.

Conclusions: Turkish women visiting PHCC are overtly and overly optimistic. This was especially obvious with the result that nearly one third had had no mammography. There is a need for further studies to understand why and how this optimism is maintained so that better screening strategies can be applied at PHCC. All health workers working at PHCC have to be aware of this optimism to prevent missed opportunities for cancer screening.
\end{abstract}

Keywords: Breast neoplasms, Screening, Prevention, Risk, Perception

\section{Background}

Breast cancer is by far the most frequent cancer among women with an estimation 1.383,5 million newly diagnosed cases in 2008 globally (23\% of all cancers), and also is the most frequent cause of cancer death in women in both developing and developed countries [1]. In Turkey breast is most common site for cancer in women with $23.3 \%$ for women and age adjusted incidence rate is highest for breast cancer and estimated as 33.7 per hundred thousand for 2006 [2]. The mortality estimation is 13.4 per hundred thousand [3].

Despite some recent controversy, most of the current literature confirms that breast cancer screening is an

\footnotetext{
* Correspondence: mehtapkartal@gmail.com

'Equal contributors

'Department of Family Medicine, Medical Faculty of Dokuz Eylul University, 35340, Inciralti, Izmir, Turkey

Full list of author information is available at the end of the article
}

effective tool for reducing breast cancer mortality [4-6]. Gaps in breast cancer knowledge, misunderstanding of related risk factors, and inaccurate perception of one's own risk may have a negative impact on screening behaviors for breast cancer. As studies begin to quantify the risks and benefits of early detection and primary prevention strategies especially among women with high risk, the women's risk perception of developing breast cancer has become increasingly important fact that can affect their choice of screening options or risk-reduction strategies [7-9].

Gail model, widely used as a risk-prediction method for estimating and calculating breast cancer risk, has been tested for different populations including diverse race and ethnic groups, and also validated for European women [10-12]. This model includes age of the woman, her age at menarche, and age at first live birth, number of first degree relatives with breast cancer, number of 
previous breast biopsies, and history of atypical hyperplasia for the estimation of breast cancer risk. Each woman's risk can be calculated using an online calculator which generates five year and life time risk scores and the corresponding risk scores for a woman of the same age who has no risk factors [13-17].

There are conflicting results about the perceptions of women, either optimistic or pessimistic, and the effects of concern and risk perception about cancer on their screening behaviors. Women with optimistic perception, underestimating their own risk, may feel invulnerable to breast cancer and mistakenly forgo the potential benefits of screening. Moreover, if a woman is underestimating her risk but is in "high risk" group can also miss the opportunity to benefit from advances of chemoprevention in breast cancer $[9,18,19]$. Conversely, women with pessimistic perception, overestimating their own risk, may suffer from unnecessary worry or unnecessary evaluations that increase the chance of false-positive results leading subsequent testing or just vice versa $[7,8,18,20-22]$.

Together with this, it is also an interesting result that the majority of women at high risk of developing breast cancer may underestimate their risk, and a substantial proportion of women at average risk may perceive that they are at increased risk [7]. But some studies have shown that the tendency of the women is leaning towards overestimating their breast cancer risk [23-25]

As the U.S. Preventive Services Task Force (USPSTF) and American Cancer Society recommend screening mammography, they consider the clinical breast exam and the breast self-examination (BSE) as a complimentary method to mammography in the context of a shared decision making and breast self-awareness of the women at average risk. Primary health care centers are the critical point of access for breast cancer screening and play a significant role in consultancy of breast health and using shared decision-making approach for cancer screening preferences of their patients [26].

The aim of the study was to evaluate the women's breast cancer risk perception and their accuracy determined by using an objective measure, Gail model, and to investigate factors that can affect their risk perception including their socio-demographic characteristics; concerns in relation to having breast cancer, and to evaluate their screening attitudes including breast self-examination and mammography.

\section{Methods}

Data was collected in a cross-sectional survey design that examined breast cancer risk factors, risk perceptions and screening behaviors, monthly regular breast-self examination and mammography at least once within a minimum period of five years, from cancer-free women aged over 45 years.
Women, during their visits to their primary health care center (PHCC), for any reason between MarchJune 2011, were invited to participate in the survey. The PHCC constitutes of 10 physicians and 11 nurses and midwives working together as a group practice. The exclusion criteria were ages below 45 and any previous personal history of breast cancer. The study was completed by 624 women having face-to-face interviews after their oral consent was taken in PHCC. Ethical approval was obtained from Dokuz Eylul University Faculty of Clinical and Laboratory Research Ethics Committee while written official permission was obtained from the Provincial Health Directorates of Izmir.

A questionnaire completed by the participants included the following: socio-demographic (age, marital status, graduation, work status) and health related characteristics (general health status, presence of first degree relatives with breast cancer, contribution of family history to breast cancer risk), risk factors included in Gail model, and screening behaviors including regular monthly BSE and mammography performance at least once within last 5 years, and breast cancer concern.

"Perceived risk" was investigated with regards to numeric and verbal measures. The numeric measure was displayed with pie charts showing risk as simple fractions, risk 1 out of 3 women (1/3), 1 out of 10 women (1/10), 1 out of 50 women (1/50), 1 out of 100 women $(1 / 100)$ and 1 out of 1000 women $(1 / 1000)$ as shown in Figure 1.The verbal measure was asked as, "What would you say about your risk having breast cancer?", and answered by 5 -point Likert scale, namely as very low, low, moderate, high, very high. For the final analyses for risk perception, these variables dichotomized to low and high risk. Low risk included $1 / 100$ and $1 / 1000$ values for numeric measure and "very low, low" replies for verbal measure, while all others included in "high risk".

Actual breast cancer risk was calculated by National Cancer Institute's Breast Cancer Risk Assessment Tool (BCRAT), also known as the Gail Model. After entering the necessary information, calculation of the women's breast cancer risk over the next five year was calculated with this tool available at the web site immediately [17]. The model predicts risk for breast cancer and for women whose 5 -year risk scores $\geq 1.67$ were considered as "increased-high risk" whiles others as "average risk". This value was used as a threshold in breast cancer prevention trials $[7,27,28]$.

Accuracy of risk perception addressed according to Gail groups, and perceived risk measures. Perceived risk categories were defined as;

- "underestimate" if women with Gail 5-year risk $\geq 1.67$ responded as "low risk"; 


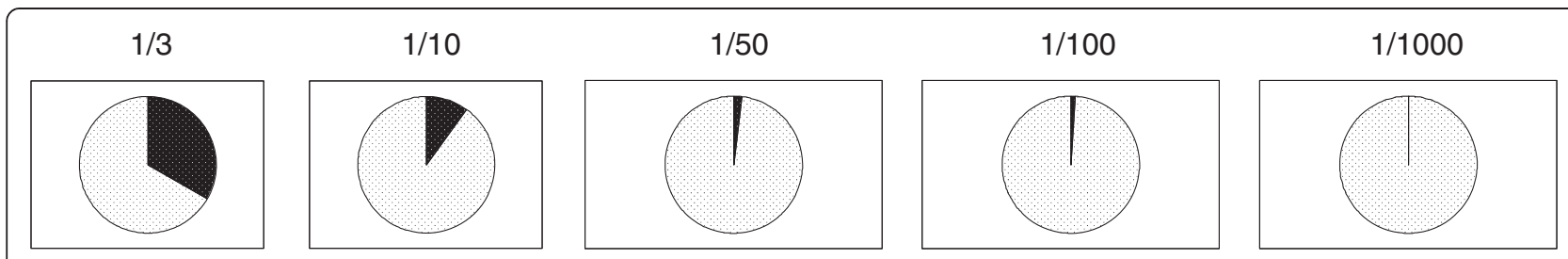

Figure 1 Numeric measure for risk perceptions of women.

- "accurate", if women with Gail 5-year risk $\geq 1.67$ responded as "high risk", or women with Gail 5-year risk $<1.67$ responded as "low risk"; and

- "overestimate" if women with Gail 5-year risk $<1.67$ responded as "high risk".

Breast cancer concern was evaluated with two items that inquired the frequency of worry and its effect on the daily life of the woman. It is scaled from 1 to 7,1 representing "not at all" and 7 being "all the time". Cronbach's alpha for the study group was 0.74 . The total score of the two items was grouped as low, average and high.

\section{Statistical analysis}

Descriptive statistics were mentioned as number and percentage, while Spearman's correlations were calculated for perceived breast cancer risks with numeric and verbal measures and objective breast cancer risk calculated with Gail model, and breast cancer concern and bivariate analysis between accuracy of perceived breast cancer risk and factors that can affect them were conducted using Pearson's chi-square and Fisher's exact test where appropriate using the Statistical Package for Social Sciences version 15. A two-sided alpha level was accepted as 0.05 for significance.

\section{Results}

The age of the participants ranged from 45 to 85 years (mean age: $59.62 \pm 1.97$ years). About one-third of the participants $(\% 35.4 ; \mathrm{n}=221)$ had graduated from primary school, most of them were not working (92.8\%; $\mathrm{n}=579$ ), and about two-third were married/living with partner $(60.6 \% ; n=378)$. Most of the women described their health as fair or good $(89.3 \% ; n=557)$. Of the women, $6.7 \%(n=42)$ had a first-degree relative with breast cancer, $52.9 \%(\mathrm{n}=330)$ defined the "contribution of family history to risk" as strong. Women who performed regular monthly BSE and had a mammography at least once within last 5 year constituted $68.9 \%(n=$ $430)$ and $62.3 \%(n=389)$ of the participants, respectively. Most of the women, $(82.9 \% ; n=517)$ expressed their breast cancer worry as "low" (Table 1). According to Gail score for 5 year breast cancer risk $22.4 \%(n=140)$ of the women were in "increased-high risk" group with a median risk score of 2.00 (Range: 1.70-4.20) and 77.6\% $(\mathrm{n}=484)$ were in "average risk" group with median Gail score 1.20 (Range: 0.50-1.60).

No differences were found between "increased-high risk" and "average risk" groups according to their health status, presence of first-degree relative with breast cancer, contribution of family history to risk assessment, screening behaviors including regular BSE and mammography performance at least once within last 5 years, and breast cancer worry level of the women participated $(\mathrm{p}>0.05)$.

Breast cancer risk perceptions of the women were assessed by a numeric and verbal measures. The lowest risk value of numeric measure, "1/1000", was mentioned by the $51.0 \%(\mathrm{n}=318)$ of the women as their perceived risk while $40.2 \%(\mathrm{n}=251)$ mentioned their risk as "very low" in verbal measure (Figure 2).

Accuracy of risk perception determination was done by using numeric measure as it had stronger correlations with worry and Gail scores (Table 2).

Most of the women, 65.5\% $(n=409)$ perceived their breast cancer risk accurately. Among the women in "increased-high risk" group according to Gail score for 5 year breast cancer risk $65.7 \%(n=92)$ underestimated their risk, while $25.4 \%(\mathrm{n}=123)$ of women in "average risk" group overestimated their risk (Figure 3).

Women aged between 45-54 years estimated their risk as "high" more than when compared to the older age groups $(\mathrm{p}<0.001)$. Women who had an education level equal to a university degree and above and who worked overestimated their risk more than the other groups $(\mathrm{p}=$ 0.019 and $\mathrm{p}=0.015$, respectively). Higher proportion $(34.4 \%)$ of the single women underestimated their risk ( $p=0.001$ ). The accuracy of breast cancer risk estimation was not affected by presence of a first-degree relative with breast cancer, health status of the women, monthly BSE and mammography performance at least once within last 5 years $(p>0.05)$. Women who described the "contribution of family history to risk" as weak were statistically inclined to significantly less overestimate their risk $(\mathrm{p}=$ 0.008). Women with "low" breast cancer worry have less overestimated their risk than other groups $(\mathrm{p}<0.001)$ (Table 3). 
Table 1 Sociodemographic and health related characteristics of women

\begin{tabular}{|c|c|c|}
\hline & $\mathrm{n}$ & $\%$ \\
\hline \multicolumn{3}{|l|}{ Age groups } \\
\hline $45-54$ & 203 & 32.5 \\
\hline $55-64$ & 237 & 38.0 \\
\hline$\geq 65$ & 184 & 29.5 \\
\hline \multicolumn{3}{|l|}{ Education } \\
\hline Illiterate & 18 & 2.9 \\
\hline Primary school & 221 & 35.4 \\
\hline Secondary school & 91 & 14.6 \\
\hline High school & 181 & 29.0 \\
\hline University and above & 113 & 18.1 \\
\hline \multicolumn{3}{|l|}{ Work status } \\
\hline Working & 45 & 7.2 \\
\hline Not working & 579 & 92.8 \\
\hline \multicolumn{3}{|l|}{ Marital status } \\
\hline Single & 32 & 5.1 \\
\hline Married/living with partner & 378 & 60.6 \\
\hline Seperated/Divorced & 63 & 10.1 \\
\hline Widowed & 151 & 24.2 \\
\hline \multicolumn{3}{|l|}{ Health status } \\
\hline Poor & 22 & 3.5 \\
\hline Fair & 277 & 44.4 \\
\hline Good & 280 & 44.9 \\
\hline Excellent & 45 & 7.2 \\
\hline
\end{tabular}

First-degree relative with breast cancer

Yes

Contribution of family history to risk

Strong

Moderate

Weak

Regular breast self-examination

Yes

Mammography within last 5 years

Yes

No

Breast cancer worry

Low

Average

High

Gail score for 5 year breast cancer risk

Average risk $(<1.67)$

Increased-high risk $(\geq 1.67)$

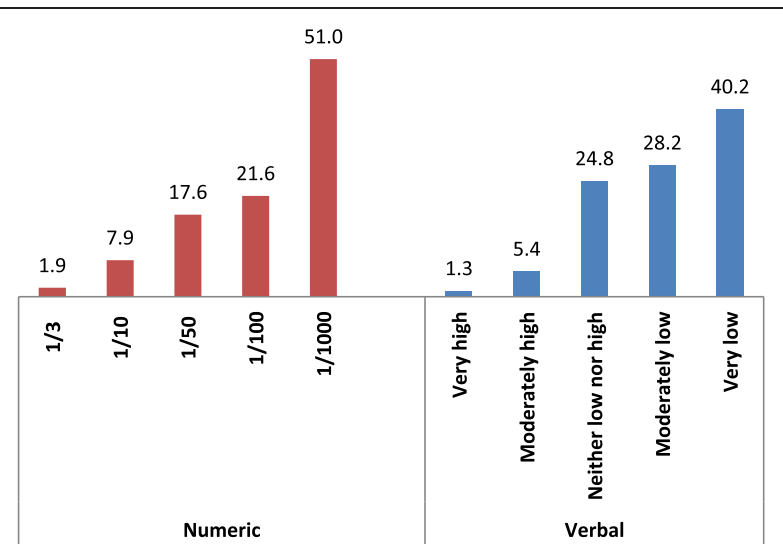

Figure 2 Numeric and verbal measures of breast cancer risk perceptions of women (\%).

\section{Discussion}

The purpose of the study was to determine the breast cancer risk perception in women and their accuracy according to the Gail model, and to examine factors that can affect their risk perception. The results revealed that, although most of the Turkish women visiting PHCC perceived their breast cancer risk accurately, the ones determined as "increased risk" were more likely to be optimistic. The women working, having higher education levels and aged between 45-54 years were overestimating their risk.

Different measures were used for risk perception including numeric, verbal, and comparative. The accuracy of risk perception is an issue that can be affected by the measure used. It was shown that numerical measure of absolute risk was more highly correlated than measures of comparative risks [24]. In this study, the numeric measure was also found to be better than verbal measure as it had a better correlation with Gail scores of the women so it was used as the accuracy measurement of risk perception of the women.

The current literature shows that women have difficulty in estimating their breast cancer risk accurately with regards to different measures used in different forms $[7,20-23,29]$. This is also true for women working as health professionals [30]. Two studies used the number 1.67 as

62.3

37.7

Table 2 Correlations of perceived and estimated breast cancer risk and worry of women

\begin{tabular}{lccc}
\hline & Numeric & Verbal & Worry \\
\hline Numeric measure & - & & \\
Verbal measure & $0.622^{* *}$ & - & \\
Breast cancer worry & $0.328^{* *}$ & $0.254^{* *}$ & - \\
Gail score & $0.117^{* *}$ & $0.083^{*}$ & -0.011 \\
${ }^{*} \mathrm{p}<0.05$. & & & \\
${ }^{* *} \mathrm{p}<0.001$. & & &
\end{tabular}




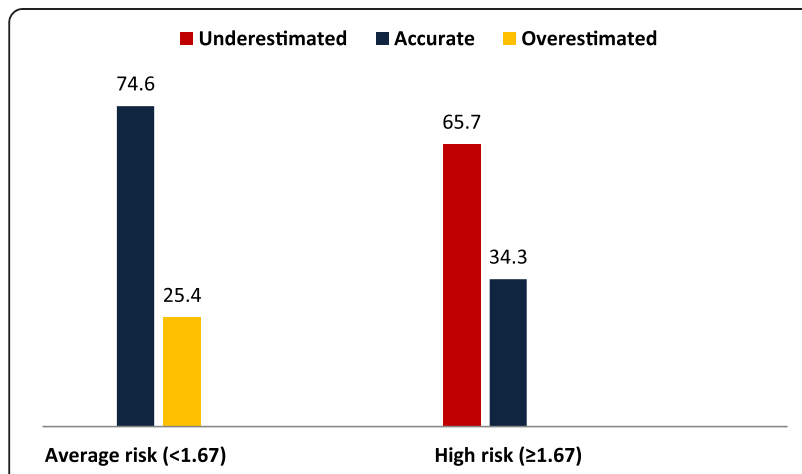

Figure 3 Distribution of accuracy of risk perceptions of women according to Gail 5-year risk scores (\%).

the cut off point for Gail 5 year risk score in relation to average and increased-high risk in comparison of perceived risk. Haas and et al. showed that among women with different race and ethnicity in average risk group with a median Gail score 1.00 (range $=0.32-1.66$ ) $28 \%$ overestimate their breast cancer risk while in increased-high risk with median Gail score 2.21 (range=1.67-12.13) 56.9\% underestimate their risk [7]. Banegas and et al. states that for Chilean women, who are among the women in the "average risk" group, in accordance with the BCRAT 5 year risk of breast cancer $13.7-22.5 \%$ overestimate whilst the "increased-high risk" group showed to underestimate by 52.6-57.9\% their breast cancer risk with absolute and comparative measures for perceived risk, respectively [11]. Another study indicated that $\leq 9 \%$ of low-average-risk women overestimated their breast cancer risk, whereas $\geq 80 \%$ of increased-high-risk women underestimated their breast cancer risk [18]. In our study, according to Gail score for 5 year breast cancer risk, women in "average risk" group overestimated their risk in similar percentages however women in "increased-high risk" group were more likely to underestimate their risk showing their optimistic view. In a meta-analysis it was found that the studies' sample concluding overestimation of breast cancer risk selected via a relative who had a history breast cancer or from a healthcare setting including a hospital, a primary care, or a genetic counseling clinic. By contrast, studies that reported an optimistic bias for the perceived risk had their samples from the community [31]. Our sample was recruited from a PHCC, and although it is a healthcare setting, our results showed the optimistic bias of the samples from the community. It is not a surprising outcome as PHCCs are the best settings that reflect our community. It seems that primary care workers including physicians, nurses and midwives have to face with the reality of the handicaps of this optimistic view of the women they meet in their daily practice.

It is obvious that women's socio-demographic characteristics can have an impact on their risk perception.
There are pros and cons in the results of studies for younger women's risk perception for breast cancer. While most of the studies reported younger ages were inversely associated with risk perception or in other words to overestimate their risk like we found $[7,9,11,18,20,32,33]$, the two studies from Turkey reported just the opposite $[30,34]$. However, a meta-analysis overall found no relationship between older age and increased perceived risk [31]. There are also controversial results for risk perception accuracy of women according to their education, marital status, and income $[9,20,29,33]$. The study population of women who were highly educated, working, married or divorced tended to show a pessimistic perception about their breast cancer risk. Researchers in their meta-analysis found that women with college education were less likely to have an optimistic bias [31].

Presence of a first-degree relative with breast cancer and the concern levels of women are the other important issues that can have affect on screening behaviors of the women. In different study populations, the percentage of first-degree relative with breast cancer changes between $2.9 \%$ and $11 \%$ [9,11,28-30]. The percentage of women performing BSE ranges between 21.3-83.7, while the percentage of women having mammography at least once changes between 20.9-78.9 [9,30,34-37]. In our study population, $6.7 \%$ of the women had a first-degree relative with breast cancer, and nearly one third of women did not perform regular monthly BSE or have a mammography at least once within last 5 years. Although high levels of cancer worry are uncommon, as found in our study, higher worry levels are not associated with reduced screening. Most of the studies reported that breast cancer worry, regardless of how it is measured, is associated with stronger likelihood of screening, mammography or BSE. However, there were exceptions including a study population of women who just had had a biopsy to determine whether they had breast cancer or not and one that found no relation between worry and BSE where $21.3 \%$ of women perform BSE regularly once a month $[34,38]$.

All studies showed that women who had risk factors for breast cancer such as previous personal history of breast disease, presence of family history of breast cancer, and being of an age over 40, having their first menstrual period at a young age, history of abnormal mammography, history of breast biopsy or morbid obesity were more likely to rate their perceived risk as "moderate-strong" or "increased" $[7,9,30-32,36]$. In our study women who had family history of breast cancer had a pessimistic perception. However, women who described the "contribution of family history to risk" as weak significantly underestimated their risk. The knowledge gap about a risk factor for breast cancer, like presence of family history of breast cancer can be a factor that effects the risk perception. 
Table 3 Distribution of accuracy of risk perceptions of women according to sociodemographic and health related characteristics

\begin{tabular}{|c|c|c|c|c|c|c|c|c|}
\hline & & \multicolumn{2}{|c|}{ Underestimated } & \multicolumn{2}{|c|}{ Accurate } & \multicolumn{2}{|c|}{ Overestimated } & \multirow[t]{2}{*}{$\mathrm{p}$-value } \\
\hline & & $\mathbf{n}$ & $\%$ & $\mathbf{n}$ & $\%$ & $\mathbf{n}$ & $\%$ & \\
\hline \multirow[t]{3}{*}{ Age groups } & $45-54$ & 8 & 3.9 & 131 & 64.5 & 64 & 31.5 & $<0.001$ \\
\hline & $55-64$ & 35 & 14.8 & 157 & 66.2 & 45 & 19.0 & \\
\hline & $\geq 65$ & 49 & 26.6 & 121 & 65.8 & 14 & 7.6 & \\
\hline \multirow[t]{5}{*}{ Education } & Illiterate & 4 & 22.2 & 14 & 77.8 & 0 & 0.0 & 0.019 \\
\hline & Primary school & 25 & 11.3 & 153 & 69.2 & 43 & 19.5 & \\
\hline & Secondary school & 18 & 19.8 & 55 & 60.4 & 18 & 19.8 & \\
\hline & High school & 22 & 12.2 & 127 & 70.2 & 32 & 17.7 & \\
\hline & University and above & 23 & 20.4 & 60 & 53.1 & 30 & 26.5 & \\
\hline \multirow[t]{2}{*}{ Work status } & Working & 1 & 2.2 & 30 & 66.7 & 14 & 31.1 & 0.015 \\
\hline & Not working & 91 & 15.7 & 379 & 65.5 & 109 & 18.8 & \\
\hline \multirow[t]{4}{*}{ Marital status } & Single & 11 & 34.4 & 20 & 62.5 & 1 & 3.1 & 0.001 \\
\hline & Married/partner & 50 & 13.2 & 239 & 63.2 & 89 & 23.5 & \\
\hline & Divorced & 7 & 11.1 & 41 & 65.1 & 15 & 23.8 & \\
\hline & Widowed & 24 & 15.9 & 109 & 72.2 & 18 & 11.9 & \\
\hline \multirow[t]{4}{*}{ Health status } & Poor & 4 & 18.2 & 13 & 59.1 & 5 & 22.7 & 0.351 \\
\hline & Fair & 41 & 14.8 & 170 & 61.4 & 66 & 23.8 & \\
\hline & Good & 41 & 14.6 & 194 & 69.3 & 45 & 16.1 & \\
\hline & Excellent & 6 & 13.3 & 32 & 71.1 & 7 & 15.6 & \\
\hline \multirow[t]{2}{*}{ 1st-degree relative with breast cancer } & Yes & 7 & 16.7 & 25 & 59.5 & 10 & 23.8 & 0.689 \\
\hline & No & 85 & 14.6 & 384 & 66.0 & 113 & 19.4 & \\
\hline \multirow[t]{3}{*}{ Contribution of family history to risk } & Strong & 44 & 13.3 & 222 & 67.3 & 64 & 19.4 & 0.008 \\
\hline & Moderate & 24 & 12.4 & 121 & 62.7 & 48 & 24.9 & \\
\hline & Weak & 24 & 23.8 & 66 & 65.3 & 11 & 10.9 & \\
\hline \multirow[t]{2}{*}{ Breast self-examination } & Yes & 62 & 14.4 & 288 & 67.0 & 80 & 18.6 & 0.499 \\
\hline & No & 30 & 15.5 & 121 & 62.4 & 43 & 22.2 & \\
\hline \multirow[t]{2}{*}{ Mammography within last 5 years } & Yes & 58 & 14.9 & 252 & 64.8 & 79 & 20.3 & 0.862 \\
\hline & No & 34 & 14.5 & 157 & 66.8 & 44 & 18.7 & \\
\hline \multirow[t]{3}{*}{ Breast cancer worry } & Low & 83 & 16.1 & 356 & 68.9 & 78 & 15.1 & $<0.001$ \\
\hline & Average & 8 & 13.6 & 25 & 42.4 & 26 & 44.1 & \\
\hline & High & 1 & 2.1 & 28 & 58.3 & 19 & 39.6 & \\
\hline
\end{tabular}

There are also conflicting results reported about the perceived risk and screening behaviors of women including adherence to BSE and mammography. Studies showed that the increased perceived cancer risk was related to increased regular breast cancer screening or mammography use $[30,32,37]$. However, even among the women with the highest projected breast cancer risk, approximately $25 \%$ did not report routine mammography use. On the other side, increased 5-year projected breast cancer risk was associated with a statistically significant increase in recent or routine mammography use $[32,36]$. The women who had had a mammogram in the last year showed both accurate and high risk perception [9,29]. However, we could not find any relationship between risk perception and regular monthly BSE or mammography performance. Katapodi et al. showed that perceived risk has a small but significant effect on mammography adherence for cancer screening. However, there were inconclusive results about the association between BSE adherence and perceived risk [31].

Greater worries about breast cancer were found to be associated with higher perceived verbal/numerical absolute risk [24]. In our study, most of the women expressed their breast cancer concern as "low", and among them those who described their worry as "low" were more optimistic than others. Women with optimistic view might feel invulnerable to breast cancer and screening guidelines [19]. 
To our knowledge, this is one of few studies which investigated the risk perception of Turkish women, and factors that can have effect on the perception of risk. However, the study has some limitations. As it has the design of a cross-sectional study, a causal relationship cannot be identified. Secondly, all study participants were recruited from a PHCC which means the results may not be generalizable to their peers in Turkey. Finally, there may have been some information bias in terms of the risk perception and worry levels because these variables were measured using self-reported questionnaires.

\section{Conclusions}

In conclusion, the current study revealed that, Turkish women, especially those in the "increased risk" group, visiting the PHCCs were more likely to underestimate their risk for breast cancer and it was found that nearly one third did not have a mammography at least once within last 5 years. Not only physicians, but also nurses and midwives working at PHCCs have to be aware of this optimism in order to prevent missed opportunities of diagnosis while consulting and managing their cancer screening. There is also a need for further studies that aim to understand why and how this optimism is maintained so that better screening strategies can be applied at PHCCs.

\section{Abbreviations}

PHCC: Primary health care center; USPSTF: U.S. Preventive Services Task Force; BSE: Breast self-exam; BCRAT: Breast Cancer Risk Assessment Tool.

\section{Competing interests}

The authors declare that they have no competing interests.

\section{Authors' contributions}

MK participated in the design, performed the statistical analysis, interpreted the findings, and involved in drafting the manuscript. NO participated in the design of the study, interpreted the findings, and involved revising the manuscript. SH and MNT participated in data collection of the study helped to draft the manuscript. ADG involved in drafting and critical revision of the manuscript. The manuscript has been seen and approved by all authors.

\section{Acknowledgment}

We wish to thank all of the women who participated in this study.

\section{Author details}

${ }^{1}$ Department of Family Medicine, Medical Faculty of Dokuz Eylul University, 35340, Inciralti, Izmir, Turkey. ${ }^{2}$ Family Medicine Specialist, Ministry of Health, 24th Family Health Center, Izmir, Turkey. ${ }^{3}$ Family Medicine Specialist, Izmir, Turkey.

Received: 2 July 2014 Accepted: 17 November 2014

Published online: 05 December 2014

\section{References}

1. Ferlay J, Shin HR, Bray F, Forman D, Mathers C, Parkin DM: Estimates of worldwide burden of cancer in 2008: GLOBOCAN 2008. Int J Cancer 2010, 127(12):2893-2917.

2. Eser S, Yakut C, Özdemir R, Karakilinç H, Özalan S, Marshall SF, Karaoğlanoğlu O, Anbarcioğlu Z, Üçüncü N, Akin Ü, Özen E, Özgül N, Anton-Culver H, Tuncer M: Cancer incidence rates in Turkey in 2006: a detailed registry based estimation. Asian Pac J Cancer Prev 2010, 11(6):1731-1739.
3. International Agency for Research on Cancer: Globocan 2012: Estimated Cancer Incidence, Mortality and Prevalence Worldwide in 2012. [http:// globocan.iarc.fr/Pages/fact_sheets_population.aspx] Accessed January 29, 2014.

4. Hackshaw AK, Paul EA: Breast self-examination and death from breast cancer: a meta-analysis. Br J Cancer 2003, 88(7):1047-1053.

5. Nelson HD, Tyne K, Naik A, Bougatsos C, Chan BK, Humphrey L, U.S. Preventive Services Task Force: Screening for breast cancer: an update for the U.S. Preventive Services Task Force. Ann Intern Med 2009, 151(10):727-737. W237-42.

6. Mukhtar TK, Yeates DR, Goldacre MJ: Breast cancer mortality trends in England and the assessment of the effectiveness of mammography screening: population-based study. J R Soc Med 2013, 106(6):234-242.

7. Haas JS, Kaplan CP, Des Jarlais G, Gildengoin V, Pérez-Stable EJ, Kerlikowske $\mathrm{K}$ : Perceived risk of breast cancer among women at average and increased risk. J Womens Health (Larchmt) 2005, 14(9):845-851.

8. Kim SE, Pérez-Stable EJ, Wong S, Gregorich S, Sawaya GF, Walsh JM, Kaplan CP: Association between cancer risk perception and screening behavior among diverse women. Arch Intern Med 2008, 168(7):728-734.

9. Park K, Chang SJ, Kim HC, Park EC, Lee ES, Nam CM: Big gap between risk perception for breast cancer and risk factors: nationwide survey in Korea. Patient Educ Couns 2009, 76(1):113-119.

10. Matsuno RK, Costantino JP, Ziegler RG, Anderson GL, Li H, Pee D, Gail MH: Projecting individualized absolute invasive breast cancer risk in Asian and Pacific Islander American women. J Natl Cancer Inst 2011, 103(12):951-961.

11. Banegas MP, Püschel K, Martínez-Gutiérrez J, Anderson JC, Thompson B: Perceived and objective breast cancer risk assessment in Chilean women living in an underserved area. Cancer Epidemiol Biomarkers Prev 2012, 21(10):1716-1721.

12. Decarli A, Calza S, Masala G, Specchia C, Palli D, Gail MH: Gail model for prediction of absolute risk of invasive breast cancer: independent evaluation in the Florence-European Prospective Investigation Into Cancer and Nutrition cohort. J Natl Cancer Inst 2006, 98(23):1686-1693.

13. Gail MH, Brinton LA, Byar DP, Corle DK, Green SB, Schairer C, Mulvihill JJ: Projecting individualized probabilities of developing breast cancer for white females who are being examined annually. J Nat/ Cancer Inst 1989 81(24):1879-1886

14. Costantino JP, Gail MH, Pee D, Anderson S, Redmond CK, Benichou J, Wieand $\mathrm{HS}$ : Validation studies for models projecting the risk of invasive and total breast cancer incidence. J Natl Cancer Inst 1999, 91(18):1541-1548.

15. Karliner LS, Napoles-Springer A, Kerlikowske K, Haas JS, Gregorich SE, Kaplan CP: Missed opportunities: family history and behavioral risk factors in breast cancer risk assessment among a multiethnic group of women. J Gen Intern Med 2007, 22(3):308-314.

16. Seyednoori T, Pakseresht S, Roushan Z: Risk of developing breast cancer by utilizing Gail model. Women Health 2012, 52(4):391-402.

17. National Cancer Institute. Breast cancer risk assessment tool. [http://www.cancer.gov/bcrisktool/]

18. Katapodi MC, Dodd MJ, Facione NC, Humphreys JC, Lee KA: Why some women have an optimistic or a pessimistic bias about their breast cancer risk: experiences, heuristics, and knowledge of risk factors. Cancer Nurs 2010, 33(1):64-73.

19. Lewis $C L$, Kinsinger LS, Harris RP, Schwartz RJ: Breast cancer risk in primary care: implications for chemoprevention. Arch Intern Med 2004 164(17):1897-1903.

20. Black WC, Nease RF Jr, Tosteson AN: Perceptions of breast cancer risk and screening effectiveness in women younger than 50 years of age. J Natl Cancer Inst 1995, 87(10):720.

21. Smith BL, Gadd MA, Lawler C, MacDonald DJ, Grudberg SC, Chi FS, Carlson K, Comegno A, Souba WW: Perception of breast cancer risk among women in breast center and primary care settings: Correlation with age and family history of breast cancer. Surgery 1996, 120(2):297.

22. Woloshin S, Schwartz LM, Black WC, Welch HG: Women's perceptions of breast cancer risk: how you ask matters. Med Decis Making 1999, 19(3):221-229

23. Lerman C, Lustbader E, Rimer B, Daly M, Miller S, Sands C, Balshem A: Effects of individualized breast cancer risk counseling: a randomized trial. J Natl Cancer Inst 1995, 87(4):286-292.

24. Lipkus IM, Kuchibhatla M, McBride CM, Bosworth HB, Pollak KI, Siegler IC, Rimer BK: Relationships among breast cancer perceived absolute risk, comparative risk, and worries. Cancer Epidemiol Biomarkers Prev 2000, 9(9):973-975. 
25. Ghosh K, Crawford BJ, Pruthi S, Williams Cl, Neal L, Sandhu NP, Johnson RE, Wahner-Roedler D, Britain MK, Cha SS, Ghosh AK: Frequency format diagram and probability chart for breast cancer risk communication: a prospective, randomized trial. BMC Womens Health 2008, 8:18.

26. Agency for Healthcare Research and Quality. [http://www.guideline.gov/ syntheses/synthesis.aspx?id=39251]

27. Fisher B, Costantino JP, Wickerham DL, Redmond CK, Kavanah M, Cronin WM, Vogel V, Robidoux A, Dimitrov N, Atkins J, Daly M, Wieand S, Tan-Chiu E, Ford L, Wolmark N: Tamoxifen for prevention of breast cancer: report of the National Surgical Adjuvant Breast and Bowel Project P-1 Study. J Natl Cancer Inst 1998, 90(18):1371-1388.

28. Levine M, Moutquin JM, Walton R, Feightner J, Canadian Task Force on Preventive Health Care and the Canadian Breast Cancer Initiative's Steering Committee on Clinical Practice Guidelines for the Care and Treatment of Breast Cancer: Chemoprevention of breast cancer: A joint guideline from the Canadian Task Force on Preventive Health Care and the Canadian Breast Cancer Initiative's Steering Committee on Clinical Practice Guidelines for the Care and Treatment of Breast Cancer. CMAJ 2001, 164(12):1681-1690.

29. Hay JL, McCaul KD, Magnan RE: Does worry about breast cancer predict screening behaviors? A meta-analysis of the prospective evidence. Prev Med 2006, 42(6):401-408.

30. Buxton JA, Bottorff $J L$, Balneaves $L G$, Richardson C, McCullum M, Ratner PA Hack T: Women's perceptions of breast cancer risk: are they accurate? Can J Public Health 2003, 94(6):422-426.

31. Webster $\mathrm{P}$, Austoker J: Women's knowledge about breast cancer risk and their views of the purpose and implications of breast screening-a questionnaire survey. J Public Health (Oxf) 2006, 28(3):197-202

32. Katapodi MC, Lee KA, Facione NC, Dodd MJ: Predictors of perceived breast cancer risk and the relation between perceived risk and breast cancer screening: a meta-analytic review. Prev Med 2004, 38(4):388-402.

33. Gross CP, Filardo G, Singh HS, Freedman AN, Farrell MH: The relation between projected breast cancer risk, perceived cancer risk, and mammography use: results from the National Health Interview Survey. J Gen Intern Med 2006, 21(2):158-164.

34. Katapodi MC, Dodd MJ, Lee KA, Facione NC: Underestimation of breast cancer risk: influence on screening behavior. Oncol Nurs Forum 2009, 36(3):306-314.

35. Jones SC, Magee CA, Barrie LR, Iverson DC, Gregory P, Hanks EL, Nelson AE, Nehill CL, Zorbas HM: Australian women's perceptions of breast cancer risk factors and the risk of developing breast cancer. Womens Health Issues 2011, 21(5):353-360.

36. Crepeau AZ, Willoughby L, Pinsky B, Hinyard L, Shah M: Accuracy of personal breast cancer risk estimation in cancer-free women during primary care visits. Women Health 2008, 47(2):113-130.

37. Yavan T, Akyüz A, Tosun N, lyigUn E: Women's breast cancer risk perception and attitudes toward screening tests. J Psychosoc Oncol 2010 28(2):189-201.

38. Ceber E, Soyer MT, Ciceklioglu M, Cimat S: Breast cancer risk assessment and risk perception on nurses and midwives in Bornova Health District in Turkey. Cancer Nurs 2006, 29(3):244-249.

doi:10.1186/s12905-014-0152-3

Cite this article as: Kartal et al.: Breast cancer risk perceptions of Turkish women attending primary care: a cross-sectional study. BMC Women's Health 2014 14:152.

\section{Submit your next manuscript to BioMed Central and take full advantage of:}

- Convenient online submission

- Thorough peer review

- No space constraints or color figure charges

- Immediate publication on acceptance

- Inclusion in PubMed, CAS, Scopus and Google Scholar

- Research which is freely available for redistribution 